\title{
Credit constraints, growth and inequality dynamics ${ }^{\sqrt{3}}$
}

\author{
Yoseph Yilma Getachew \\ Department of Economics, University of Pretoria, 0028, Pretoria, South Africa, e-mail: \\ yoseph.getachew@up.ac.za, tel.: +27760722472
}

\begin{abstract}
This paper examines how credit constraints affect the dynamics of wealth and thereby the dynamics of capital and output growth. We develop standard $A k$ growth models that display transitional dynamics, contrary to general belief, once the complete credit markets assumption is relaxed. The mechanism is that credit constraints make individual productivity differences persist, which in turn leads to the persistence of income inequality. The dynamics of inequality is jointly determined with the dynamics of aggregate capital. The economy thus passes through a transitional period of inequality, individual and aggregate capital dynamics before it converges to a long-run balanced growth path. The application of the model to the analysis of intergenerational mobility and inequality dynamics suggests substantial economic and policy significance. In particular, introducing credit constraints to the Barro $A k$ model, public investment could have an indirect impact on growth via its effect on inequality and mobility.
\end{abstract}

Key words:

Incomplete markets, inequality dynamics, intergenerational mobililty, Transitional dynamics, $A k$ growth model

JEL Classification: D3, E1, O4

\footnotetext{
We benefitted from comments on an earlier version of the paper from the participants at the Southern Workshop in Macroeconomics, University of Auckland, Auckland, NZ. Thanks are specially due to Parantap Basu, Stephen Turnovsky and two anonymous referees. The usual disclaimer applies.
} 


\section{Introduction}

Perhaps the most important assumption in neoclassical growth models is that firms invest to the point that their marginal rate of return to investment equates the economy's interest rate. Implicit in this assumption is the existence of complete capital markets. There are at least two problems with such an assumption. The first is that it may not fit reality well. In fact, credit constraints pervade the economic activities of most of the developing world. Even in advanced economies, credit market frictions could exist due to the substantially high cost of administrating credit. This is particularly evident from many empirical works that find that firms' investment falls below the level of investment required to equate the marginal rate of return to capital with that of the market interest rate. According to Mel et al. (2008), for instance, in Sri Lanka the average real return to capital is about 60 percent per year, for a set of micro-enterprises, much higher than the market interest rate. The return to capital for a set of Indian firms is estimated at greater than 90 percent, which is twice as high as the market interest rate (Banerjee and Duflo, 2004). McKenzie and Woodruff (2006), using Mexican micro-enterprises, argue that not only is the marginal product of capital significantly different from that of the market interest rate but also that the returns to capital among different-sized firms are not equal. ${ }^{1}$

Second, it undermines a considerable amount of individual dynamics. The complete capital market assumption, implicit in standard growth models, implies that individual dynamics often coincide with aggregate dynamics. As a result, the models easily admit a representative-agent framework that increases their tractability substantially, although it could also restrict their applicability to inequality and mobility studies. $^{2}$ The present paper aims to contribute towards this line of thought. The paper in particular introduces credit constraints to endogenous growth models, which lead the models to show an uncharacteristically rich transitional dynamics emanating from individual differences. It also shows that, when applied to the analysis of growth and the distributional impact of public investment policy, this could have a substantial economic and policy implication.

\footnotetext{
${ }^{1}$ They estimate 15 percent per month return to capital for firms with investment capital of less than $\$ 200 ; 7$ to 10 percents per month for firms with investment capital between $\$ 200$ and $\$ 500 ; 5$ percent per month for firms with investment capital between $\$ 500$ and $\$ 1000$. They estimate the market interest rate at 3 percent per month.

${ }^{2}$ One of the few exceptions is the work by Caselli and Ventura (2000), which allows a distributional analysis within a representative-agent framework where aggregate equilibrium becomes the determinant force of the evolution of wealth and income inequality. See Garcia and Turnovsky (2007) and Chatterjee and Turnovsky (2012) for applications of this model.
} 
We thus examine how credit constraints affect the dynamics of wealth and thereby the dynamics of capital and output growth. We develop a standard $A k$ growth model that displays transitional dynamics, contrary to the general belief, once the complete credit markets assumption is relaxed. The main mechanism is that credit constraints make individual productivity differences persist, which in turn leads to a persistent inequality. The dynamics of inequality is jointly determined with the dynamics of aggregate capital. The economy thus passes through a transitional period of inequality, individual and aggregate capital dynamics before it converges to a long-run balanced growth path.

The $A k$ growth model is arguably the basis of every endogenous growth model. It has been the workhorse model of economic growth during the last two decades. ${ }^{3}$ Particularly, it provides a convenient framework for understanding policy issues in relation to long-run growth (see, for instance, Barro, 1990 and Turnovsky, 1996, 1997, among many others). In spite of such popularity, the model in its simplest form has been criticized for a lack of transitional dynamics that appears to be an empirical regularity (e.g., Mankiw, Romer and Weil, 1992).

Under the assumption of perfect capital markets, the standard $A k$ growth model in the spirit of Romer (1986) and Barro (1990), with diminishing returns at the individual household level but constant returns at the aggregate level, has no transitional dynamics. All aggregate variables - aggregate consumption, capital and output grow at a constant rate at all times. A perfect capital market implies an instantaneous equalization of intra- and inter-temporal individual household productivity in the economy, as individuals trade capital, in a Pareto-efficient way, until the point where their productivity differences vanish. It fixes the rate of return to capital to a constant market interest rate. The economy thus jumps to its long-run balanced growth path at the first period.

Credit constraints, on the other hand, make initial individual productivity differences prevail. The intuition is that, with imperfect credit market, individuals with low endowment and hence with a high marginal rate of return could not borrow, from individuals with the opposite trait, and invest more efficiently. A higher initial wealth inequality thus relates to a greater inefficiency (lower growth), as it leads the economy to forgo more productive investment opportunities. Differences in marginal productivity tend to generate differences in growth rates among individual

\footnotetext{
${ }^{3}$ As is well known, the model introduced into the modern literature through the seminal works of Romer (1986), Rebelo (1991) and Barro (1990). According to Aghion and Howitt (1998, p. 26), the model was first introduced by Frankel (1962), although Barro and Sala-i-Martin (2004, p. 63) think that the production function was first used by Neumann (1937).
} 
households. This leads to inequality dynamics, which becomes the driving force of aggregate capital dynamics. Along the transition to a steady state, the economy features a declining inequality since individuals with relatively lower initial endowment rapidly accumulate wealth due to their relatively high marginal productivity.

The result is remarkably robust to alternative environments. In particular, in an economy where households have a finite life span and preferences are non-homothetic (as in the Stone-Geary utility function), credit constraints play an important role in inequality and growth dynamics in $A k$ models but through a different mechanism. Such an economy features two different consumers, a non-Ricardian household whose consumption decisions entail consuming the full amount of its labor income as it falls below subsistence consumption, and a Ricardian household whose optimal decisions are based on its budget constraints. As the economy grows and its capital stock expands, the productivity of the poor increases via trickle down growth, eventually leading inequality to converge and the economy to function at its full potential in equilibrium.

Introducing credit constraints to the Barro (1990) $A k$ model, public investment policy could have an indirect impact on growth via its effect on inequality and mobility. This is in addition to the standard productivity and complementarity effects often mentioned in the literature. Higher inequality corresponds to lower growth when the credit and insurance markets are missing, as these prevent the efficient amount of investment to be undertaken in the economy. In this case, egalitarian public investment policy has a positive impact on growth through its effect on mitigating inequality. However, such an effect is compromised due to its negative impact on individual productivity.

A quantitative analysis of the model suggests that public investment has nontrivial effects on intergenerational mobility and inequality. A strong negative distributional effect from public capital could double steady-state inequality and intergenerational elasticity. The model's prediction of mobility and inequality is quite consistent with that of many estimates in intergenerational mobility and inequality, particularly when the public investment is pro-rich. In such cases, much slower and more plausible transitional dynamics are obtained vis-à-vis an exceedingly fast speed of dynamics implied by a private pre-existing condition.

The paper contributes to the understanding of whether and, ultimately, how capital market imperfections affect the dynamics of $A k$ growth models, and their implication for policy analysis. With few exceptions, previous works often abstract from capital market imperfections. ${ }^{4}$ For instance, Turnovsky (1997) considers a small

\footnotetext{
${ }^{4}$ See Tamura (1991), Carroll et al. (1997, 2000), Boucekkine et al. (2005), Gomez (2008) and
} 
open economy that faces an upward-sloping supply curve for debt in a Barro-type $A k$ model. In the model, the borrowing interest rate increases with the debt-capital ratio of the borrowing nation. There would be a transitory dynamics in the economy through an adjustment in the debt-capital ratio that drives the interest rate to a level at which the growth rate is equalized. Therefore the mechanism is different from the current paper, where persistence of individual productivity differences, due to credit constraints and diminishing returns to investment at the individual firm level, is the driving force behind aggregate dynamics.

The paper relates to the literature of imperfect credit markets, inequality and growth, particularly with respect to linking inequality dynamics to the dynamics of aggregate capital and output, although this literature does not focus on transitional dynamics in $A k$ models. ${ }^{5}$ The paper is also related to the recent literature on inequality, growth and public investment (e.g., García-Peñalosa and Turnovsky, 2007, Chatterjee and Turnovsky, 2012, Getachew, 2010, and Getachew and Turnovsky, 2015). ${ }^{6}$ Getachew and Turnovsky (2015) study the distributional and growth effects of public investment in a growth model with missing capital markets and a CES production function, where both growth and inequality are endogenously determined. In the paper, the effects of public investment policy on inequality and growth depend on the elasticity of substitution between between public and private capital. This is in contrast to the current paper, which emphasizes policy targeting.

The rest of the paper proceeds as follows. Section 2 sets up a growth model, with missing credit markets, which is $A k$ at the aggregate level as the production function at the firm level is augmented by an economy-wide externality. Section 3 mainly examines transitional dynamics in the general $A k$ model. Section 4 relaxes the missing credit market assumption by allowing households some borrowing. Section 5 studies the model's closed-form solution to reveal various interesting transitional properties of the $A k$ model at both the individual household and aggregate levels. Section 6 looks into the policy application of the model by introducing credit constraints to

Guerrini (2010), which were all written independently of our study. Jones and Manuelli (1990), for instance, used a production function that asymptotically displays an $A k$ model.

${ }^{5}$ See, for example, Loury (1981), Galor and Zeira (1993), Banerjee and Newman (1993), Aghion et al. (1999), Matsuyama (2000), Benabou (2002), Giannini (2003), Getachew (2010), Bandyopadhyay and Tang (2011) and Shin (2012).

${ }^{6}$ García-Peñalosa and Turnovsky (2007), and Chatterjee and Turnovsky (2012) study the impact of growth-enhancing fiscal policies on inequality, but within a complete market framework that follows the line of Caselli and Ventura (2000). Getachew (2010), on the other hand, considers incomplete capital markets although his analysis is restricted to short-run effects, as the model does not feature idiosyncratic uninsurable risks. 
the Barro model, and studies its quantitative relevance. Section 8 considers an alternative environment where preferences are non-homothetic and households have a finite life span. Section 8 draws conclusions.

\section{The Model}

\subsection{The Romer-Barro Ak technology}

The main property of a typical $A k$ production function is the absence of diminishing returns to capital at the aggregate level. In an economy with $A k$ technology, the marginal product of aggregate capital is constant at $k$, at all times. Therefore the economy could display long-run growth without transitional dynamics. Two main reasons are often provided for the global absence of diminishing returns to capital: (i) $k$, in the $A k$ function, could represent broad capital that includes both physical and human capital and/or (ii) the production function at the individual firm level could be augmented by an economy-wide externality (such as the learning-by-doing technology of Arrow, 1962). ${ }^{7}$

The latter in particular is the basis of the Romer (1986) and Barro (1990) endogenous growth models, and many others after them. This class of model in general could be characterized by a production function that features diminishing returns at the individual firm level but constant returns at the aggregate economy level. The production function at the firm level is a function of both private and social capital, each facing diminishing-returns. The social capital often assumes spillover effects of aggregate capital (Romer, 1986) or a public investment as a fraction of aggregate output (Barro, 1990). Most importantly, however, at the economy-wide level capital escapes diminishing returns and, hence, the model generates endogenous growth.

\subsection{The production function}

In the spirit of Romer (1986), we suppose the production function of the $i$ th firm has the following constant return technology:

$$
\begin{aligned}
& y_{t}^{i}=k_{t} f\left(k_{t}^{i} / k_{t}\right)=k_{t} f\left(\varphi_{t}^{i}\right) \\
& k_{t} \equiv \int_{i} k_{t}^{i}=\mathrm{E} k_{t}^{i} ; \varphi_{t}^{i} \equiv k_{t}^{i} / k_{t} ; \varphi_{t}=1 \\
& y_{t}=A_{t} k_{t} ; A_{t} \equiv \operatorname{Ef}\left(\varphi_{t}^{i}\right)
\end{aligned}
$$

\footnotetext{
${ }^{7}$ See Barro and Sala-i-Martin (2004, p. 63-66, 205-235) for a detailed discussion.
} 
where $k_{t}^{i}$ and $y_{t}^{i}$ are the firm's capital and output, respectively; and $y_{t}$ is aggregate output. $^{8}$

There exist diminishing returns to factors at the individual firm level:

$$
\partial y_{t}^{i} / \partial k_{t}^{i}=f_{\varphi_{t}^{i}}^{\prime}\left(\varphi_{t}^{i}\right)>0 ; f_{\varphi_{t}^{i}}^{\prime \prime}\left(\varphi_{t}^{i}\right)<0
$$

However, at the aggregate level, constant returns to capital apply. This is the reason for $A k$ models' capability of generating endogenous growth but also their 'lack' of transitional dynamics. This implies that $A_{t}-$ the rate of return to aggregate capital - is not a function of $k_{t}$. The marginal product of aggregate capital $\left(\partial y_{t} / \partial k_{t}\right)$ does not thus vary with changes in $k_{t}$ at all times.

\subsection{Preference and household optimization}

We suppose a continuum of infinitely-lived heterogeneous households. The $i$ th household is initially endowed with $k_{0}^{i}$ units of capital and a unit of inelastic labor. It supplies both to a privately owned firm. Households are thus both consumers and entrepreneurs. Therefore the capital markets are missing, in the spirit of Benabou (1996). Such individual entrepreneurship is not uncommon in the literature (see, for instance, Benabou, 2000, 2002, Angeletos and Calvet, 2005, 2006 and Bandyopadhyay and Tang, 2011). However, the absence of any (inter- or intra-temporal) capital market could be quite extreme, which is the price to pay for analytical tractability of the model. In the next section, we relax this assumption and adopt the more realistic capital market imperfection that permits households some borrowing and lending.

To simplify aggregation, let the distribution of initial wealth take lognormal probability distribution

$$
\ln k_{0}^{i} \sim N\left(\mu_{0, k}, \sigma_{0, k}^{2}\right)
$$

We use $\sigma_{k}^{2}$, which is the variance of the logarithm of capital, to measure wealth inequality, whereas $\sigma_{y}^{2}$ and $\sigma_{c}^{2}$ denote income and consumption inequality, respectively.

The $i$ th dynasty maximizes her utility in accordance with the constant intertemporal elasticity of substitution (CIES) utility function,

$$
u\left(c_{t}^{i}\right) \equiv \sum_{t=0}^{\infty} \beta^{t}\left(\left(c_{t}^{i}\right)^{1-\theta}-1\right) /(1-\theta)
$$

subject to the budget constraint

\footnotetext{
${ }^{8}$ Variables with(out) superscript $i$ represent individual (aggregate) values. We use the operators $\int_{i}$ and $\mathrm{E}$ interchangeably to denote aggregation across individuals.
} 


$$
c_{t}^{i}+k_{t+1}^{i}=y_{t}^{i}
$$

where capital is fully depreciated, and $c_{t}^{i}, k_{t+1}^{i}$ and $y_{t}^{i}$ are household consumption, saving and income, respectively.

The solution to the optimization problem leads to the Euler equation,

$$
c_{t+1}^{i} / c_{t}^{i}=\left(\beta \partial y_{t+1}^{i} / \partial k_{t+1}^{i}\right)^{1 / \theta}
$$

which ${ }^{9}$ characterizes the optimal dynamics of the economy at the individual household level.

\section{Transitional dynamics in $A k$ models with missing credit markets}

\subsection{Inequality dynamics}

Eq. (6) is a standard condition from the perspective of the household optimization problem. But, given the missing capital markets and (2), it also features the distributional dynamics of the economy. Particularly, households with different levels of initial capital follow different paths of growth. Due to diminishing returns to investment, individuals with a higher level of capital face a lower productivity and, hence, a lower growth rate. Such productivity differences are persistent under the missing credit market.

The inequality generated in such a manner is the source of transitional dynamics in the $A k$ economy, as it determines the paths of aggregate consumption and capital. The persistence of individual household productivity differences drives inequality dynamics in this economy. Taking the log and the variance of (6), one sees that:

$$
\mathrm{V} \ln \left(c_{t+1}^{i} / c_{t}^{i}\right)=\left(1 / \theta^{2}\right) \mathrm{V} \ln \left(\partial y_{t+1}^{i} / \partial k_{t+1}^{i}\right)
$$

Differences in marginal productivity thus lead to differences in growth rates among individual households. The former, which also depends on the degree of diminishing returns to capital at the individual household level is highly persistent due to the missing credit market, which limits individual investment opportunities to the resources they have in hand. In the case of a perfect market, however, individuals will trade capital, in a Pareto-efficient way, until the point where their productivity differences disappear. As we see later on, such productivity differences will vanish instantaneously under a perfect credit market.

\footnotetext{
${ }^{9}$ Together with the transversality condition.
} 
Proposition 1. The Romer Ak model described above displays inequality dynamics under a missing credit market via its effect on the persistence of individual household productivity differences.

Proof. Proven in the text.

\subsection{Capital dynamics and steady state}

The dynamics of aggregate capital is jointly determined with the dynamics of inequality. This is evident from the fact that steady-state equilibrium cannot be reached in this economy in the presence of inequality.

Definition 1. A steady state in the Ak growth model is a balanced growth path where aggregate consumption $\left(c_{t}\right)$, capital $\left(k_{t}\right)$ and output $\left(y_{t}\right)$ grow at a constant rate, $\gamma+1$ $\equiv c_{t+1} / c_{t}=y_{t+1} / y_{t}=k_{t+1} / k_{t}$.

Proposition 2. The Ak model described above will be in a steady-state equilibrium iff $\sigma_{t+1}^{2}=\sigma^{2}=0$.

Proof. Suppose the economy is on the balanced growth path where $\ln \left(c_{t+1} / c_{t}\right)$ is constant but $\sigma_{t+1, k}^{2} \neq 0$. The latter implies that there is at least one individual $l$ who has a larger capital than that of the average person $\left(k_{t+1}<k_{t+1}^{l}\right)$. Thus, from (6) and (2), $\ln \left(c_{t+1} / c_{t}\right)>\ln \left(c_{t+1}^{l} / c_{t}^{l}\right)$. This is because individual households with low levels of capital grow faster due to diminishing returns. The catching-up continues, though at a declining rate as the wealth gap closes. But this contradicts $\ln \left(c_{t+1} / c_{t}\right)$ is constant on the balanced growth path; therefore $\sigma_{t+1, k}^{2}=\sigma_{k}^{2}=0$. Considering (1a) and (5), if $\sigma_{k}^{2}=0$, then $\sigma_{y}^{2}=0$ and $\sigma_{c}^{2}=0$. It is straightforward that if $\sigma^{2}=0$, the model jumps to its balanced growth path, as shown below in Section 4.

The following Corollary then immediately follows from the above two Propositions:

Corollary 1. The Romer Ak model displays transitional dynamics under a missing credit market via its effect on inequality persistence.

Therefore, absent the dynamics of inequality, the model behaves similarly to any of the standard $A k$ models, jumping to its balanced growth path at the first period. ${ }^{10}$ Second, the economy will not be on its steady-state equilibrium balanced

\footnotetext{
${ }^{10}$ We discuss this in detail in Section 4 , which shows how the economy behaves under perfect and imperfect credit markets.
} 
growth path unless the dynamics of inequality reaches its equilibrium. The latter is thus an important determinant of the dynamics of aggregate variables in the economy. Third, a degenerate distribution is what actually happens in the long run. This is quite intuitive as there are no factors in this model that lead to a non-degenerate equilibrium wealth distribution. ${ }^{11}$ Individual households differ only in terms of initial capital but are similar otherwise. Individuals with relatively lower $k_{t}^{i}$ rapidly accumulate wealth due to their relatively high marginal productivity, which is, in turn, due to diminishing returns to investment. Therefore the economy features a declining inequality along the transition to a steady state.

\subsection{Growth-inequality trade-offs}

It is intuitive that the decline in inequality as the economy approaches its longrun growth path is accompanied by an increase in the growth rate of the economy. ${ }^{12}$ In such an economy, inequality is negatively related to growth as imperfection in the capital markets prevents the optimal amount of investment to be undertaken. Diminishing returns to investment imply that the poor have a higher marginal product than the rich. A higher inequality thus relates to a greater inefficiency as it leads the economy to forgo more productive investment opportunities.

\section{Imperfect credit markets}

The absence of any capital trade in the previous section is an oversimplified representation of capital market incompleteness. In this section, we allow individuals to have some access for credit. By allowing some households to borrow, we are assuming the loan contract is enforceable. One way to deal with this problem is to consider that lenders could seize some income of the borrows. This is often modelled in the literature as households can borrow only a fraction of their labor income. ${ }^{13}$

Suppose individual households are allowed to borrow and lend with a gross market interest rate of $R_{t}$. Then the budget constraints that the $i$ th household faces become

$$
\begin{aligned}
c_{t}^{i}+k_{t+1}^{i}+q_{t+1}^{i} & =y_{t}^{i}+q_{t}^{i} R_{t} \\
q_{t+1}^{i} & \geq-\phi y_{t+1}^{i}
\end{aligned}
$$

\footnotetext{
${ }^{11}$ Section 5 introduces idiosyncratic shocks that lead to such an outcome.

12 This will be proved in Section 5, applying a closed-form solution to the model.

${ }^{13}$ See, for instance, Aiyagari (1994), Jappelli and Pagano (1994) and De Gregorio (1996), among others.
} 
where $\phi \geq 0$ measures the degree of financial market development, in the spirit of Aiyagari (1994). $k_{t+1}^{i}$ and $q_{t+1}^{i}$ represent a portfolio of capital and bonds, respectively. ${ }^{14}$ Eq. (9) restricts the individual to carry over a negative asset (debt) beyond a certain amount. If $\phi=0$ or $q_{t+1}^{i} \geq 0$ then we have a no-borrowing constraint. The individual can be a lender but not a borrower. On the other hand, when $\phi$ approaches to $\infty$ there will be a perfect capital market, with no restriction on the amount of debt to carry over to the next period.

The optimization problem leads to (see Appendix B),

$$
u^{\prime}\left(c_{t+1}^{i}\right) \beta r_{t+1}^{i} \frac{1-\phi R_{t+1}}{1-\phi r_{t+1}^{i}}=u^{\prime}\left(c_{t}^{i}\right)
$$

where $r_{t+1}^{i} \equiv \partial y_{t+1}^{i} / \partial k_{t+1}^{i}$ is the individual marginal rate of return to investment that determines its productivity rate. Eq. (10) is simply a modified Euler equation, adjusted for the imperfection in the capital market.

First note that, with a no-borrowing constraint, $\phi=0,(10)$ becomes

$$
u^{\prime}\left(c_{t+1}^{i}\right) \beta r_{t+1}^{i}=u^{\prime}\left(c_{t}^{i}\right)
$$

which simply takes us to the previous case of a missing credit market. In this case, all the analysis and the results in Section 3 apply. On the contrary, if $\phi \rightarrow \infty$, then the borrowing constraint (9) is no longer binding. Applying the L'Hospital's rule in (11), we find

$$
u^{\prime}\left(c_{t+1}^{i}\right) \beta R_{t+1}=u^{\prime}\left(c_{t}^{i}\right)
$$

Thus the ratio of inter-temporal marginal utility is constant across individuals. This condition, which is similar to the optimization problem without borrowing constraints, also implies the following no-arbitrage equilibrium condition (see Appendix B):

$$
r_{t+1}^{i}=R_{t+1}
$$

For two individuals $i$ and $j$, this means:

\footnotetext{
${ }^{14}$ The set-up is different from Aiyagari, though. There is no portfolio capital investment but a single asset $\left(a_{t}^{i}\right)$ in Ayagari (1994), where the budget contraint is given by $c_{t}^{i}+a_{t+1}^{i}=y_{t}^{i}+a_{t}^{i} R_{t}$; and $a_{t+1}^{i} \geq-\phi$ is the borrowing constraint. In this case, $\phi$ is said to be the "natural debt limit" when it takes the life-cycle income of the individual.
} 


$$
R_{t+1}=r_{t+1}^{i}=r_{t+1}^{j}
$$

Therefore each individual trades capital until her marginal rate of return to capital equals the market interest rate of capital, which is Pareto efficient. Eq. (14) also implies that each individual invests the same amount of capital $\left(k_{t+1}^{i}=k_{t+1}^{j}=k_{t+1}\right)^{15}$ and, consequently, will have the same amount of income $\left(y_{t+1}^{i}=y_{t+1}^{j}=y_{t+1}\right)$. In this case, the rate of return of capital related to each firm is constant and fixed at the market interest rate. Thus, considering (1a), we have

$$
\partial y_{t+1}^{i} / \partial k_{t+1}^{i}=\partial y_{t+1} / \partial k_{t+1}=f(1)=R
$$

Then, substituting (15) into the Euler equation (6), with CIES utility, we will finally arrive at the condition that

$$
c_{t+1}^{i} / c_{t}^{i}=c_{t+1} / c_{t}=(\beta R)^{1 / \theta}
$$

Initial inequality vanishes instantaneously and the model does not feature any transitional dynamics. It turns into a representative-agent-type economy where a representative household owns a representative firm. In Barro and Sala-i-Martin (2004, p. 208), it is shown that the economy has no transitional dynamics and jumps to its balanced growth path at the initial period where $c_{t+1} / c_{t}=k_{t+1} / k_{t}=y_{t+1} / y_{t}$. The consumption- and output-capital ratios $\left(c_{t} / k_{t}\right.$ and $y_{t} / k_{t}$, respectively) are thus constant at any point in time. Therefore, if there is a perfect credit market, the model will have no transitional dynamics. The marginal rate of return to capital related to every firm will be fixed at the market interest rate under a perfect credit market. Therefore all individual quantities grow at a constant and a similar rate, which is also the rate of growth of the economy, at all times.

Finally, for the general case $\phi \in(0, \infty)$, we can rewrite the modified Euler equation in (10) as

$$
c_{t+1}^{i} / c_{t}^{i}=\left(\beta \widetilde{r}_{t+1}^{i}\right)^{1 / \theta}
$$

where

\footnotetext{
${ }^{15}$ The proof is straightforward: Suppose $i$ and $j$ invest different amount of capital, $k_{t+1}^{i} \gtrless k_{t+1}^{j}$ while (14) holds. Due to the existence of diminishing returns to capital at the firm level, this implies $\partial y_{t+1}^{i} / \partial k_{t+1}^{i} \lessgtr \partial y_{t+1}^{j} / \partial k_{t+1}^{j}$, which contradicts (14).
} 


$$
\begin{aligned}
\widetilde{r}_{t+1}^{i} & \equiv r_{t+1}^{i} d_{t+1}^{i} \\
d_{t+1}^{i} & \equiv\left(1-\phi R_{t+1}\right) /\left(1-\phi r_{t+1}^{i}\right)
\end{aligned}
$$

where $\widetilde{r}^{i}$ measures the individual effective productivity rate that determines its growth rate. ${ }^{16}$ The weight $d^{i}$ depends on the the level of financial development $(\phi)$ and the relative financial position of an individual (whether $r^{i} \lessgtr R$ ).

Individuals with $r^{i}>R$ are natural borrowers. Since they command marginal rates of return to capital higher than the market interest rate, they have the potential to borrow, invest and repay the debt with interest higher or equal to the market interest rate. Their growth rate increases as the credit constraint is more relaxed (as $\phi$ increases). ${ }^{17}$ In contrast, individuals with $r^{i}<R$ invest lesser and lesser as $\phi$ increases, as they prefer trading assets than investing on their own. Their growth rate rather tends to decline as $\phi$ increases. Therefore a more relaxed credit market could speed up the process of convergence.

Loglinearizing (17), around $r_{t}^{i}=R_{t}{ }^{18}$ could give a further insights into the dynamics of inequality:

$$
\ln c_{t+1}^{i} / c_{t}^{i} \approx \ln \beta R+(\theta(1-R \phi))^{-1}\left[\ln r_{t+1}^{i}-\ln R\right]
$$

Taking the log and the variance of (19), one sees that

$$
\mathrm{V} \ln \left(c_{t+1}^{i} / c_{t}^{i}\right) \approx(\theta(1-R \phi))^{-2} \mathrm{~V} \ln \left(\partial y_{t+1}^{i} / \partial k_{t+1}^{i}\right)
$$

Again, we find the two polar cases in (20), for $\phi=0$ and $\lim \phi \rightarrow \infty$, which represent a missing and a perfect credit market, respectively. For the intermediate case, $\phi \in(0, \infty)$, (20) is comparable to $(7)$, where individual differences in marginal productivity are associated with differences in growth rates leading to inequality dynamics. Therefore the extreme form of market incompleteness that we have seen in the previous section is not a necessary condition for the model to display transitional dynamics, but all that really matters is that there exists some imperfection.

To conclude, the lack of transitional dynamics in the standard $A k$ model is basically due to lack of movement in the rate of return to aggregate capital. The presence of a perfect capital market creates the instantaneous equalization of the intra- and

\footnotetext{
${ }^{16}$ We suppress the time subscripts for simplicity.

${ }^{17}$ This could be confirmed as $\widetilde{r}^{i}$ increases in $\phi$ if $r^{i}>R$, and conversely.

${ }^{18}$ This also implies that we are loglinearizing around $k_{t}^{i}=k_{t}, c_{t}^{i}=c_{t}$ and $y_{t}^{i}=y_{t}$.
} 
inter-temporal individual household productivities in the economy and fixes the rate of return to aggregate capital to the market interest rate. Credit imperfection in the capital markets, however, causes initial individual productivity differences to persist, which in turn leads to inequality dynamics. The dynamics of inequality is jointly determined with the dynamics of aggregate capital. Thus the growth rates of aggregate variables are not always constant during the transition periods but evolve with inequality at different rates, until the economy reaches its long-run growth path.

\section{Closed-form solution}

This section examines the Romer $A k$ dynamics in a closed-form solution using a Cobb-Douglas production function, a logarithm preference and a missing credit market. We also introduce idiosyncratic shocks that lead to a non-degenerate equilibrium distribution. The model features different interesting properties at both the individual household and aggregate levels during the transition periods. Particularly, dynasties with different levels of initial capital follow different paths of capital, consumption and income growth. The growth rates of individual household consumption and income are always the same but different from that of capital. The economy, on the other hand, experiences a unique path of inequality that drives the dynamics of the rest of the macroeconomic variables. Aggregate consumption and output grow at the same rate but higher (lower) than that of aggregate capital if the economy starts from a higher (lower) level of inequality. Individual and aggregate capital dynamics eventually converge to unique and stable equilibria.

\subsection{Cobb-Douglas technology and logarithm preference}

When the production function (1a) is Cobb-Douglas, we have

$$
y_{t}^{i}=a_{1} \epsilon_{t}^{i} k_{t}\left(k_{t}^{i} / k_{t}\right)^{\alpha}
$$

where $a_{1}>0$, and $\epsilon_{t}^{i}$ is the $i$ th firm idiosyncratic shock, which is i.i.d and assumed to be lognormally distributed: $\ln \epsilon_{t}^{i} \sim N\left(-\nu^{2} / 2, \nu^{2}\right)$.

Thus the Euler equation $(6)$ is given by $(\theta=1)$ :

$$
\gamma_{t+1, c}^{i}+1 \equiv c_{t+1}^{i} / c_{t}^{i}=a_{1} \beta \alpha \epsilon_{t+1}^{i}\left(k_{t+1}^{i} / k_{t+1}\right)^{\alpha-1}
$$

Together with (5) and (21), this gives closed-form solutions:

$$
\begin{aligned}
k_{t+1}^{i} / k_{t}^{i} & =a_{1} \beta \alpha \epsilon_{t}^{i}\left(k_{t}^{i} / k_{t}\right)^{\alpha-1} \\
c_{t}^{i} & =a_{1}(1-\beta \alpha) \epsilon_{t}^{i} k_{t}\left(k_{t}^{i} / k_{t}\right)^{\alpha}
\end{aligned}
$$


Aggregating (23) yields the dynamics of aggregate capital investment (see Appendix A):

$$
\gamma_{t+1, k}+1 \equiv k_{t+1} / k_{t}=a_{1} \beta \alpha \exp \left(\alpha(\alpha-1) 0.5 \sigma_{t, k}^{2}\right)
$$

Taking the $\log$ and then the variance of (23) yields the distributional dynamics associated with capital investment:

$$
\sigma_{t+1, k}^{2}=\alpha^{2} \sigma_{t, k}^{2}+\nu^{2}
$$

From (25) and (26), one sees immediately that the dynamics of inequality drives the dynamics of aggregate capital in the $A k$ economy. The two form a system of dynamic equations that characterizes the transitional dynamics of the economy. Given $\alpha \in(0,1)$, the system is stable and converges to a unique stable steady state. In contrast to the previous section, there is now a positive steady-state inequality due to individual differences in luck $\left(\epsilon_{t}^{i}\right)$.

\subsection{Individual dynamics}

Eqs. (23), (25) and (26) characterize the dynamics at the individual level. The dynamics of aggregate capital and inequality determine the evolutions of individual consumption and capital growth. The intuition lies in the presence of externality effects in the economy. The effect of inequality on individual households is channeled through its effect on aggregate capital (25), whereas the latter has a direct impact on individual household productivity (21).

From (21), (23) and (24), individual capital investment $\left(k_{t+1}^{i}\right)$, consumption $\left(c_{t}^{i}\right)$ and income $\left(y_{t}^{i}\right)$ grow at the same rate at all times:

$$
\begin{aligned}
k_{t+1}^{i} & =(\beta \alpha /(1-\beta \alpha)) c_{t}^{i} \\
c_{t}^{i} & =(1-\beta \alpha) y_{t}^{i}
\end{aligned}
$$

Similarly, from aggregating (27) and (28), aggregate capital investment $\left(k_{t+1}\right)$, consumption $\left(c_{t}\right)$ and output $\left(y_{t}\right)$ grow at the same rate.

However, as we shall soon see, the behavior of the $A k$ economy at the individual firm level is not necessarily similar to that of the aggregate. Growth dynamics at the individual firm level has rather peculiar features that are not reflected at the aggregate level. This is because individual production functions face marginal diminishing returns to capital whereas the aggregate economy features a constant return. Moreover, aggregate variables are directly involved in the evolution of individual variables via the externality effects of aggregate capital on household productions. 
Behind the Ak dynamics. The current model has three distinct features (vis-à-vis the standard $A k$ model). All are attributed mainly to credit market imperfections. First, the growth rate of the current-period individual capital investment is lower than that of the previous periods in this model. In a growing economy, the level of current capital associated with an individual is higher than that of the previous periods. When this is coupled with diminishing returns to capital investment and capital market imperfections, the former grows more slowly than the latter. Second, two different family dynasties follow different growth paths in our model. Individual households with a lower level of initial capital experience a relatively higher growth rate of capital due to the imperfection in the capital markets and diminishing returns to capital. Finally, because of these two, there are two types of inequality dynamics in the current model: cross-sectional inequality at a given moment of time and intergenerational inequality - the variation of income or wealth across generations.

\subsubsection{Growth rates comparison}

Leaving the effects of individual luck aside $\left(\epsilon_{t}^{i}=1\right)$, one can compare the growth rates of consumption, income and capital investment at the individual firm level. First, rewrite (21) as

$$
\gamma_{t+1, y}^{i}=(1-\alpha) \gamma_{t+1, k}+\alpha \gamma_{t+1, k}^{i}
$$

where $\gamma_{t+1, z}^{i} \equiv \ln \left(z_{t+1}^{i} / z_{t}^{i}\right) .{ }^{19}$ Then, from (28) and (29), one sees that, during the transition periods, individual consumption and income grow at the same rate, whereas they grow at different rates from that of capital, depending on the relative position of the particular individual in the economy:

Proposition 3. $\gamma_{k}^{i} \geq \gamma_{c}^{i}=\gamma_{y}^{i}$ during transition if the ith individual capital is below average, $k_{t}^{i}<k_{t} \exp \left(0.5 \alpha \sigma_{t, k}^{2}\right)$. Otherwise, $\gamma_{k}^{i} \leq \gamma_{c}^{i}=\gamma_{y}^{i}$. The equality holds if $k_{t}^{i}=k_{t} \exp \left(0.5 \alpha \sigma_{t, k}^{2}\right)$.

Proof. It is evident from (28) that $\gamma_{y}^{i}=\gamma_{c}^{i}$. Rewrite (29) as $\gamma_{y}^{i}=\gamma_{k}^{i}+(1-\alpha)\left(\gamma_{k}-\gamma_{k}^{i}\right)$. Thus, $\gamma_{k}^{i} \lesseqgtr \gamma_{y}^{i}$ iff $\gamma_{k} \gtreqless \gamma_{k}^{i}$. But, from (23) and (25), $\gamma_{k} \gtreqless \gamma_{k}^{i} \Leftrightarrow \ln k_{t+1} / k_{t} \gtreqless \ln k_{t+1}^{i} / k_{t}^{i}$ iff $k_{t}^{i} \gtreqless k_{t} \exp \left(0.5 \alpha \sigma_{t, k}^{2}\right)$.

The term $k_{t}^{i} \exp \left(-0.5 \alpha \sigma_{t, k}^{2}\right)$ represents the average inequality-adjusted capital. If the $i$ th individual were the average person, she would have suffered $\exp \left(0.5 \alpha \sigma_{t, k}^{2}\right)$

\footnotetext{
${ }^{19}$ In what follows, we omit the time subscript from the gamma variables when no confusion arises. For instance, we write $\gamma_{k}^{i}$ instead of $\gamma_{t+1, k}^{i}$ to represent the growth rate of the $i$ th capital at $t+1$.
} 
efficiency loss of capital investment due to inequality via credit market imperfections. Substituting $k_{t}=k_{t}^{i} \exp \left(-0.5 \alpha \sigma_{t, k}^{2}\right)$ into (21), one sees that her income would have also been compromised: $y_{t}^{i}=a_{1} k_{t}^{i} \exp \left(0.5 \alpha(\alpha-1) \sigma_{t, k}^{2}\right) \cdot{ }^{20}$

\subsection{Aggregate dynamics, equilibrium, inequality and growth}

The dynamics of aggregate capital and inequality are shown in (25) and (26). We can also aggregate the Euler equation (see Appendix A):

$$
\ln \left(c_{t+1} / c_{t}\right)=a_{1} \beta \alpha \exp \left(0.5\left(\sigma_{t+1, c}^{2}-\sigma_{t, c}^{2}+(1-\alpha) \sigma_{t+1, k}^{2}-\nu^{2}\right)\right)
$$

From (26), (27) and (28), it is straightforward that

$$
\sigma_{t, y}^{2}=\sigma_{t, c}^{2}=\sigma_{t+1, k}^{2}=\alpha^{2} \sigma_{t, k}^{2}+\nu^{2}
$$

Using this, we obtain

$$
\gamma_{t+1, c}=a_{1} \beta \alpha \exp \left(0.5 \alpha(\alpha-1)\left(\alpha^{2} \sigma_{t, k}^{2}+\nu^{2}\right)\right)
$$

From (25) and (32), we obtain

$$
c_{t+1} / k_{t+1}=\left(c_{t} / k_{t}\right) \exp \left(0.5(\alpha-1) \alpha\left(\left(\alpha^{2}-1\right) \sigma_{t, k}^{2}+\nu^{2}\right)\right)
$$

Therefore the aggregate consumption-capital ratio $\left(c_{t} / k_{t}\right)$ is not constant, as $\sigma_{t, k}^{2}$ continues to evolve during the transition periods.

The growth rate of aggregate output is given, from aggregating (21), and considering (25), by

$$
\gamma_{t+1, y}=a_{1} \beta \alpha \exp \left(0.5 \alpha(\alpha-1)\left(\alpha^{2} \sigma_{t, k}^{2}+\nu^{2}\right)\right)
$$

Proposition 4. (i) $\gamma_{t+1, c}=\gamma_{t+1, y} \gtrless \gamma_{t+1, k}$ iff $\sigma_{t, k}^{2} \gtrless \nu^{2} /\left(1-\alpha^{2}\right)$. (ii) In the steady state, the economy remains on a balanced growth path where all variables grow at the same rate and inequality remains constant:

$$
\sigma_{k}^{2}=\nu^{2} /\left(1-\alpha^{2}\right)
$$

Proof. (i) From (32) and (34), $\gamma_{t+1, c}=\gamma_{t+1, y}$. It is straightforward to derive (35) from (26). Using (33) and (35), one sees that $\gamma_{t+1, c} \gtrless \gamma_{t+1, k}$ iff $\sigma_{t, k}^{2} \gtrless \nu^{2} /\left(1-\alpha^{2}\right)$.

\footnotetext{
${ }^{20}$ This can be confirmed by aggregating (21); the latter is similar to the average income of the economy.
} 
(ii) Substituting (35) into (25), (32) and (34), one gets

$$
\gamma_{k}=\gamma_{c}=\gamma_{y}=a_{1} \beta \alpha \exp \left(-0.5 \alpha \nu^{2} /(1+\alpha)\right)
$$

Therefore, during the transition periods, aggregate output and consumption grow faster than aggregate capital if the economy starts from a higher level of inequality $\left(\sigma_{t, k}^{2}>\sigma_{k}^{2}\right)$, and conversely. On the other hand, the long-run growth rate of the economy is a balanced growth path where all aggregate variables grow at the same rate.

Proposition 5. A higher level of inequality leads to lower growth, both during the transition period of the economy and in the steady-state.

Proof. From (34) to (36), an increase in the variance of the idiosyncratic shocks or inequality is associated to a lower growth rate.

A higher $\sigma_{k}^{2}$ leads households to forgo more productive investment opportunities due to credit market imperfections. Inequality has thus a negative effect on the economy, as the imperfection in the capital markets prevents the optimal amount of investment to be undertaken.

\section{Policy relevance}

In this section, we study the model's implications for policy analysis. We demonstrate this by introducing market imperfections to the Barro (1990) Ak model, which leads the model to have a rich transitional dynamics. We then apply the model to the analysis of growth and distributional impact of public investment policy. Barro's framework has been widely used in the literature to analyze the role of public investment in long-run growth. ${ }^{21}$ In addition to the conventional productivity and complementarity effects typically emphasized in this literature, we show that public investment may affect growth through an indirect channel of affecting inequality.

In the Barro model, the externality effects emanate from infrastructure investment $\left(g_{t}\right)$ by the government as a fraction of the total output

$$
g_{t}=\tau y_{t}
$$

\footnotetext{
${ }^{21}$ See, for instance, Glomm and Ravikumar (1994), Turnovsky (1996, 1997), Garcia-Penalosa and Turnovsky (2007), Agenor (2010), Bodman et al. (2012), among others.
} 
where $y_{t}=\int_{i} y_{t}^{i}$ is aggregate income, $y_{t}^{i}$ is the $i$ th individual before tax income and $\tau$ is a proportional tax levied by the government to finance the public capital. The household's after tax income is given by $(1-\tau) y_{t}^{i}$.

Further, assume that the use and efficiency of the public service is different among different households. Depending on its type, a given public service could benefit certain households more than proportionally. It could disproportionately benefit the poor due to their lack of access to its private substitutes; or the rich due to their greater access to its complements. Internet provision by the public sector may disproportionately benefit those individuals who own laptops, for instance. On the other hand, provision of public transport may benefit the poor more than proportionally as they are the ones who might lack these basic inputs.

Let the production function associated to the $i$ th firm be given by

$$
y_{t}^{i}=\epsilon_{t}^{i} a_{1}\left(k_{t}^{i}\right)^{\alpha}\left(g_{t}^{i}\right)^{\theta}
$$

where

$$
g_{t}^{i}=g_{t} /\left(k_{t}^{i}\right)^{\eta}
$$

and $\eta \in(-\infty, \infty) . g_{t}^{i}$ represents the government public service provision from the perspective of the $i$ th household. An additional parameter restriction,

$$
\alpha+\theta(1-\eta) \leq 1
$$

could be imposed to ensure that the production function exhibits diminishing or constant returns to scale.

From (39), the parameter $\eta$ features the redistributive nature of the public service. The direction and magnitude of $\eta$ determines the type and the intensity of the disproportionate impact of the provision of the public service on the individual production function, respectively. The case $\eta>0(\eta<0)$ is related to public services that benefit the poor (the rich) more than proportionally, whereas $\eta=0$ implies a proportional effect.

From (38) and (39), we obtain

$$
y_{t}^{i}=\epsilon_{t}^{i} a_{1}\left(k_{t}^{i}\right)^{\kappa}\left(g_{t}\right)^{\theta}
$$

where

$$
\kappa \equiv \alpha-\theta \eta>0
$$

Note that, with a constant-returns-to-scale production function, (41) is similar 
to $(21)$ except that aggregate capital $\left(k_{t}\right)$ is replaced by the infrastructure variable $\left(g_{t}\right)$, which is a fraction of aggregate income $\left(y_{t}\right)$. Substituting (37) into (41) and then aggregating yields

$$
y_{t}=A_{t} k_{t}
$$

where

$$
A_{t} \equiv\left(a_{1}\right)^{1 / \kappa} \tau^{(1-\kappa) / \kappa} \exp \left(0.5(\kappa-1) \sigma_{t, k}^{2}\right)
$$

which is not a function of $k_{t}$.

From (27), (28), (37), (41) and (43), individual capital dynamics is given by

$$
k_{t+1}^{i}=\epsilon_{t}^{i} a_{1}(1-\tau) \beta \alpha\left(\tau A_{t}\right)^{1-\kappa}\left(k_{t}^{i}\right)^{\kappa}\left(k_{t}\right)^{1-\kappa}
$$

Then, the dynamics of income is easily derived from (37), (41), (43) and (44):

$$
y_{t+1}^{i}=\epsilon_{t+1}^{i} a_{1}((1-\tau) \beta \alpha)^{\kappa}\left(y_{t}^{i}\right)^{\kappa}\left(\tau y_{t+1}\right)^{\theta}
$$

Eq. (45) has a direct implication for intergenerational mobility. The intergenerational elasticity of income $(\kappa)$ is derived from (45), first by taking logs from both sides of the equation, and then computing the partial derivative of the next-period income with respect to the current income:

$$
\kappa \equiv \partial \ln y_{t+1}^{i} / \partial \ln y_{t}^{i}
$$

where $1-\kappa$ is a measure of intergenerational income mobility. According to (46), the intergenerational income elasticity is independent of idiosyncratic shocks, but it depends crucially on the policy parameters of $\eta$ and $\theta$. Particularly, intergenerational income mobility increases with a pro-poor public policy (higher $\eta>0$ ) and higher $\theta$ through the effect on the private factor share of capital, $\alpha$.

From (44), the distributional and aggregate capital dynamics are derived, respectively:

$$
k_{t+1} / k_{t}=(1-\tau) \beta \alpha A_{t}
$$

and

$$
\sigma_{t+1, k}^{2}=\kappa^{2} \sigma_{t, k}^{2}+\nu^{2}
$$

Eqs. (47) and (48), which are in the spirit of (25) and (26), determine the distributional dynamics in the Barro (1990) $A k$ growth model with missing credit markets. 
Then the long-run inequality and growth are given, from (48) and (47), respectively, by

$$
\sigma^{2}=\nu^{2} /\left(1-\kappa^{2}\right)
$$

and

$$
\gamma+1=\beta \alpha a^{1 / \kappa} \tau^{(1-\kappa) / \kappa}(1-\tau) \vartheta
$$

where

$$
\vartheta \equiv \exp \left(-0.5 \nu^{2} /(1+\kappa)\right) \in(0,1)
$$

$\vartheta$ represents the negative impact of inequality.

Proposition 6. (i) A higher $\eta>0$ (egalitarian public investment policy) will have a positive influence on the dynamics of and equilirbium inequality. (ii) The impact on growth is ambiguous: While it increases growth through mitigating inequality, it decreases growth through lowering the marginal productivity of capital.

Proof. If $\eta>0$, (i) then $\sigma_{t+1, k}^{2}$ and $\sigma^{2}$ decrease in $\eta$ (ii) whereas the terms $|\vartheta|$ and $a^{1 / \kappa} \tau^{(1-\kappa) / \kappa}$, in $\gamma$, increase and decrease in $\eta$, respectively. Also, it can be confirmed from (41) that the higher $\eta>0$, the lower the marginal productivity of $k_{t}^{i}$ will be.

Therefore public investment policy could have an indirect impact on growth through its effect on inequality. A higher inequality corresponds to a lower growth as the imperfection of the capital markets prevents the efficient amount of investment to be undertaken in the economy. Government policy could indirectly affect growth by mitigating or aggravating inequality. This is in addition to the standard productivity and crowding-out effects often found in the literature.

\subsection{Numerical analysis}

Further insights could be obtained into the importance of policy, and the quantitative effects of $\eta$ and $\theta$, to mobility and inequality dynamics and equilibrium vis-à-vis the private pre-existing condition, from calibrating the model with parameter values that seem reasonable for real economies. Because growth is different for the $A k$ economy with and without inequality, it would also be interesting to see the effects of eliminating the idiosyncratic shocks and hence long-run inequality on steady-state growth.

Table 1 summarizes our calibration of the parameters. The discount factor, $\beta$, is set at 0.96 . The choice of $a_{1}$ targets a long-run growth rate of about 1.8 percent. 
This matches the average annual long-run growth rate of the US economy. The share of capital, $\alpha$, is set at 0.33 . The value for the elasticity of public capital widely varies among empirical estimates. We follow Getachew and Turnovsky (2015) and set $\theta=0.1$ and 0.2 , which encompass a large set of the estimates; ${ }^{22}$ we also set $\nu^{2}$ at 0.16 following this literature, which implies a 0.4 standard deviation for the logarithm of total factor productivity (TFP) shocks. There are no estimates regarding the value of $\eta$. We consider $\eta=0$ (a private pre-existing condition) as a benchmark and use a range of values that relates to different values of intergenerational elasticity, inequality dynamics and equilibrium. Note that, given the above calibration, only two values of $\eta$ match the constant-return-to-scale production function. These are $\eta=-5.7$ and -2.35 when $\theta=0.1$ and 0.2 , respectively - the only two cases that generate long-run growth given our calibrated values.

\section{TABLE 1 HERE}

Table 2 shows the effects of policy on intergenerational mobility and inequality dynamics and equilibrium by comparing the private pre-existing conditions $(\eta=0)$. The effects of policy on mobility and inequality mainly depend on the values of the policy and structural parameters, $\eta$ and $\theta$, respectively. Particularly, $\eta=0$ implies no policy role in inequality or mobility. ${ }^{23}$ This is shown in Table 2 as the values of intergenerational elasticity, $\kappa$, the speed of inequality convergence, $\kappa^{2}$, and long-run inequality, $\sigma^{2}$, remain constant at 0.33 and 0.11 and 0.18 , respectively, regardless of the values of the elasticity of public capital, $\theta$. The intergenerational elasticity and inequality increase sharply as $\eta$ declines (as public investment tends to favor the rich more). The higher the elasticity of public capital (the higher $\theta$ ), the stronger the effects of policy $(\eta)$ on mobility and inequality become. ${ }^{24}$ Compared to the preexisting condition, a negative distributional effect of public capital of the magnitude of $\eta=-2$ almost doubles the steady-state inequality and more than doubles the intergenerational elasticity when $\theta=0.2$.

\section{TABLE 2 HERE}

\footnotetext{
${ }^{22}$ They argue that this is consistent with the empirical estimates provided by Bartelsma et al. (2013) for seven developed countries including the UK and the US.

${ }^{23}$ This is in contrast to Getachew and Turnovsky (2015), in which the public-private capital ratio and the tax rate play a central role in determining the distributional dynamics and equilibrium. Despite its advantage of full tractability, the Cobb-Douglas assumption in the current model is quite restrictive due to its unitary elasticity of substitution assumption when it comes to distributional analysis.

${ }^{24}$ This is intuitive given (42).
} 
The model's prediction of mobility is quite consistent with that of many estimates in intergenerational mobility, particularly for negative values of $\eta$. The estimates for intergenerational elasticity $(\kappa)$ vary widely due to differences in data, methodology and various other factors. ${ }^{25}$ Solon (1992), for instance, estimated the intergenerational elasticity for the US at about 0.4. But using data of earning histories of parents and children, Mazumder (2005) estimates it at about 0.6. He argues that earlier estimates of intergenerational elasticity are biased down by approximately 30 percent due to persistent transitory fluctuations. Tamura et al. (2014), on the other hand, provide a wide range of values for intergenerational elasticity, from 0.16 to 0.54 for different countries across the world. Such a wide range of estimates could be explained, in the context of the current model, due to variation in public investment policy. As shown in Table 2, intergenerational elasticity varies between 0.18 and 0.57 as $\eta$ varies between 1.5 and -2.35 and when $\theta=0.1$. A higher value for $\theta$ even predicts higher values for intergenerational elasticity. For instance, if $\theta=0.2$, then $\eta=-2$ and -2.35 imply that $\kappa$ ranges between 0.73 and 0.8 , in line with Clark and Cummins (2012) who estimate $\kappa$ at between 0.7 and 0.8 for the UK.

The parameter values $\eta=-2.35$ and $\theta=0.2$ imply 0.44 variance of log income, which is consistent with the recent inequality in the US. Assuming a lognormal distribution of income, the mean-median ratio implies 0.4 average log-income variance for the US for the years 1979, 1986, 1991, 1994, 1997 and 2000, based on the Luxembourg Income Study (UNU-WIDER, 2007). The fact that most countries have average log-income variances of more than 0.2 implies that public investment could have been more pro-rich in these countries. A smaller $\eta$ also implies a higher coefficient for income dynamics $\left(\kappa^{2}\right)$. The speed of this dynamics implied by the private pre-existing condition $(\eta=0)$ is exceedingly fast. A slower and more plausible transitional dynamics could be obtained with a strong negative distributional effect from public capital.

\section{FIGURE 1 HERE}

Figure 1 illustrates the public investment-growth relationship for two economies, as $\tau$ ranges between 0.04 and 0.2 , for the two cases of the public elasticity of output, when $\theta=0.1$ and 0.2 . The dashed line corresponds to the benchmark economy $\left(v^{2}=0.16\right)$, whereas the solid line represents an economy without long-run inequality, obtained by eliminating the idiosyncratic shocks entirely $\left(v^{2}=0\right)$. In both cases,

\footnotetext{
${ }^{25}$ Basu and Getachew (2015) attribute this partly to the adjustment cost of human capital and to public education policy.
} 
growth first increases with $\tau$, reaches a maximum, after which it declines monotonically. For every value of $\tau$, the presence of inequality and idiosyncratic shocks $\left(v^{2} \neq 0\right)$ is associated with lower growth. Particularly, the long-run growth rates increase by 4.38 and 4.63 percentage points when $\theta=0.1$ and 0.2 , respectively, by eliminating the idiosyncratic shocks. ${ }^{26}$

\footnotetext{
${ }^{26}$ There is a large literature that emphasizes the importance of idiosyncratic shocks to the macroeconomy, particularly related to the welfare cost of the business cycle. See, for instance, Atkeson and Phelan (1994), Storesletten et al. (2001), Krebs (2003), Turnovsky and Bianconi (2005) and Krusell et al. (2009), who document a substantial welfare cost of the business cycle related to idiosyncratic shocks. However, measuring the welfare cost of the business cycle is beyond the scope of this paper.
} 


\section{Credit constraints and $\boldsymbol{A} k$ dynamics with non-homothetic preferences}

In this section, we show that the key result that borrowing constraints play an important role in inequality and $A k$ dynamics continues to hold in alternative settings. In particular, we study the model in a different environment where households have a finite life span and preferences are non-homothetic and take a Stone-Geary form.

We thus suppose an economy populated with one-period-lived heterogenous agents with a continuum dynasty. Each individual is born endowed with a unit of time. ${ }^{27}$ An individual who is born at time $t$ has a unit of labor that she supplies to the representative firm inelastically and earns the wage rate $\omega_{t}$. The individual may also earn an interest income $r_{t} x_{t}^{i}$ in case of inherited wealth $\left(x_{t}^{i}\right)$ where $r_{t}$ is the interest rate. Otherwise her total income constitutes only her wage income. She then allocates her income optimally between consumption $\left(c_{t}^{i}\right)$ and a bequest $\left(b_{t}^{i}\right)$ to her only child.

\subsection{Households}

The $i$ th individual who is born at time $t$ has the following version of the StoneGeary utility function: ${ }^{28}$

$$
\ln \left(c_{t}^{i}-s\right)+\beta \ln b_{t}^{i}
$$

where $b_{t}^{i}$ is her saving in the form of the bequest that she leaves for her offspring; $c_{t}^{i}$ is her consumption. $s$ is referred to as "subsistence" consumption, below which the individual is not allowed to consume. The utility is subject to the budget constraint

$$
c_{t}^{i}+b_{t}^{i}=w_{t}+r_{t} x_{t}^{i}
$$

The individual maximizes (51) subject to (52), taking as given prices $\left(\omega_{t}, r_{t}\right)$ and inheritance $x_{t}^{i}$. The optimal bequest $\left(b_{t}^{i *}\right)$ is given by

$$
b_{t}^{i *}=a\left(w_{t}+x_{t}^{i} r_{t}-s\right)
$$

where $a \equiv \frac{\beta}{1+\beta}$. If the individual has no inherited wealth $\left(x_{t}^{i}=0\right)$, her optimal saving function is given by $b_{t}^{i *}=a\left(w_{t}-s\right)$. Eq. (53) together with (51) imply

\footnotetext{
${ }^{27}$ We get the same results if we consider overlapping generations with two-period-lived individuals, as an adult and a child. In this case, all economic decisions are made by the adults where children's consumption is included in that of their parents.

${ }^{28}$ One might rather opt for a "Kaldorian-Keynesian" saving function, as in Galor and Moav (2004).
} 
that individuals with total income below the subsistence level $s$ will not leave any bequest, particularly if they face a borrowing constraint. ${ }^{29}$ Thus effective savings in the economy are given by

$$
b_{t}^{i}=\max \left(0, b_{t}^{i *}\right)
$$

Therefore, with credit market imperfection, the economy features two types of consumers. The first are non-Ricardian households whose consumption decision entails consuming the full amount of their labor income, and do not leave any bequest to their descendants, as their income falls below subsistence consumption. The second are Ricardian households whose optimal decisions are based on their budget constraint and thus leave bequests to their descendants, as their income exceeds their subsistent consumption.

\subsection{Firms}

We suppose a perfectly competitive representative firm that produces the final output using $A k$ technology,

$$
y_{t}=A k_{t}
$$

The firm's optimal prices are thus given by

$$
\begin{aligned}
w_{t} & =(1-\alpha) A k_{t} \\
r_{t} & =\alpha A
\end{aligned}
$$

where $1-\alpha$ and $\alpha$ are the factor shares of labor and capital, respectively. ${ }^{30}$

We suppose at the beginning that there are $z$ rich individuals who are born with a certain inheritance $\left(x^{i}>0\right)$. The rest of the population size $1-z$ are thus poor, born without any inheritance. We also assume that individuals are ex ante homogeneous within groups. Thus their descendants are also homogeneous. In this case, the total amount of capital investment in the period is simply the sum of inheritance of the rich, $k_{0}=x_{0}^{i} z$.

Considering (53), (54) and (56), the threshold levels of capital beyond which an individual leaves bequest could be derived as

$$
k=\left\{\begin{array}{c}
\bar{k}=z s / A(z(1-\alpha)+\alpha) \text { if } x^{i}>0 \\
\overline{\bar{k}}=s /(1-\alpha) A \text { if } x^{i}=0
\end{array}\right.
$$

\footnotetext{
${ }^{29}$ Individuals may not be able to borrow due to enforcement problems, as children would not be held responsible for their parents' debt.

${ }^{30}$ Alternatively, one may consider a large number of heterogeneous firms that are price takers (where the $i$ th firm production function takes the form $y_{t}^{i}=A k_{t}^{\alpha} k_{t}^{i 1-\alpha}$ ) to get the same result.
} 
Individuals do not leave bequests if the capital stock in the economy is below $\bar{k}$ or $\overline{\bar{k}}$, depending on which group they descend from. Since $\bar{k}<\overline{\bar{k}}$, the descendants of the rich have a better chance of leaving bequests to their offspring than their compatriots.

\subsection{Aggregate capital dynamics and equilibrium}

Two conditions represent the intergenerational linkage in the economy. First, individuals' ability to leave bequests depend on the current level of capital stock in the economy. Second, the total amount of bequests left by the current generation forms the next-period aggregate capital investment. In particular,

$$
k_{t+1}=z b_{t}^{r}+(1-z) b_{t}^{p}
$$

where $b_{t}^{r}$ and $b_{t}^{p}$ denote bequests left by the rich and poor, respectively.

Given (53), (56), (57) and (58), the dynamics of capital can be summarized for different threshold level:

$$
k_{t+1}=\left\{\begin{array}{c}
0 \text { if } k_{t}<\bar{k} \\
a\left((z(1-\alpha)+\alpha) A k_{t}-z s\right) \text { if } \bar{k}<k_{t}<\overline{\bar{k}}>0 \\
a\left(A k_{t}-s\right) \text { if } k_{t}>\overline{\bar{k}}
\end{array}\right.
$$

If the capital stock at time $t$ is below $\bar{k}$, then there will be no capital investment in the next period, $t+1$, as there will be no bequest, $b_{t}^{r}=b_{t}^{p}=0$. If $\bar{k}<k_{t}<\overline{\bar{k}}$, the next-period capital investment is the total amount of bequests left by the rich, $k_{t+1}=z b_{t}^{r}{ }^{31}$ If $k_{t}>\overline{\bar{k}}$, then the total capital investment constitutes the total amount of bequests left by the poor and the rich as shown in (58).

Figure 2 depicts the dynamics of aggregate capital in the economy, as given by (59), which is characterized by multiple equilibria. As shown in the horizontal bold straight line, $k_{t+1}=0$ for any initial capital $k_{t}<\bar{k}$. If the economy starts slightly higher than $\bar{k}$, however, there will be $k_{t+1} \neq 0$. But, since $k_{t+1}<k_{t}$, the dynamics goes back to its stable equilibrium, where $k_{t+1}=k_{t}=0$. For the economy to escape the low equilibrium, it should start from an initial level of capital that ensures $k_{t+1} \geq k_{t}=\widetilde{\bar{k}}$. This threshold could be derived from (59):

$$
\widetilde{\bar{k}}=\frac{s z}{A(z(1-\alpha)+\alpha)-1 / a}
$$

\footnotetext{
${ }^{31}$ Recall that $k_{t}=x_{t}^{r} z$ and $b_{t}^{r}=a\left(w_{t}+x_{t}^{r} r_{t}-s\right)$ where $x_{t}^{r}$ is the inheritance of the rich.
} 
where

$$
A(z(1-\alpha)+\alpha)-1 / a>0
$$

Thus TFP should be sufficiently large to ensure the economy escapes a poverty trap.

Note that considering (57), (60) and (61) $\overline{\bar{k}}>\widetilde{\bar{k}}>\bar{k}$. This implies, first, not all of the population should be rich descendant for economic development to kicksoff. Second, the existence of some rich people will not ensure trickled-down-growth. Third, the greater the TFP, the lower initial capital to be required for the economy escape a poverty trap.

\section{FIGURE 2 HERE}

Figure 2 shows that as the economy continuous to grow, as long as the initial capital stock exceeds $\widetilde{\bar{k}}$, it passes the threshold required for the poor to begin leaving bequest $\left(k_{t}>\overline{\bar{k}}\right)$ due to a boost in their labor income. Eventually the economy grows at its fullest potential as captured in the $p$ curve as all individuals leave bequest and hence contribute to capital investment in the economy. Finally, capital growth asymptotically approaches the long-run growth rate of the economy, $\gamma=a A-1 .{ }^{32}$

Therefore when preferences are non-homothetic and take a Stone-Geary form, credit constraints play an important role in inequality and growth dynamics in $A k$ models, but through a different mechanism. Such an economy features two different consumers, a non-Ricardian households whose consumption decisions entail consuming the full amount of their labor income as it falls below subsistence consumption, and a Ricardian households whose optimal decisions are based on its budget constraints. As the economy grows and its capital stock expands, the productivity of the poor increases via trickle down growth, eventually leading inequality to converge and the economy to function at its full potential in equilibrium.

\section{Conclusion}

The complete capital market assumption, implicit in standard growth models, often undermines a considerable amount of individual and aggregate dynamics, which could restrict the models' applicability to income inequality and intergenerational mobility studies. This is particularly evident from the properties of many $A k$ endogenous growth models. The $A k$ model is arguably the basis of every endogenous

\footnotetext{
${ }^{32}$ It can be confirmed from (59) that the slope of the $p$ curve is higher than that of the $n$ curve, which is greater than one. Note also that, given assumption (61), $a A>1$.
} 
growth model. The model often lacks transitional dynamics, which appears to be an empirical regularity, merely due to the imposition of a perfect capital market. A perfect capital market is associated with an instantaneous equalization of intra- and inter-temporal individual household productivity in the economy. It fixes the rate of return to capital to the market interest rate that leads the economy to converge to its long-run equilibrium path without transition. Capital market imperfections, on the other hand, make initial individual productivity differences persist across time and space. Consequently, there will be two types of inequalities in the economy: cross-sectional inequality at a given moment of time and intergenerational inequality - the variation of income or wealth across generations. The dynamics of inequality is jointly determined with the dynamics of aggregate capital. Therefore the introduction of credit constraints in a simple and widely applied $A k$ growth model leads the model to display a rich transitional dynamics. Such a result is remarkably robust when using an alternative environment, where households have a finite life span and preferences are non-homothetic. The model's application to the analysis of growth and public investment has shown a substantial economic and policy significance. Introducing credit constraints to the Barro $A k$ model, public investment policy could have an indirect impact on growth via its effect on inequality. This is in addition to the standard productivity and complementarity effects on private capital. A numerical analysis of the model suggests that public investment policy has nontrivial effects on intergenerational mobility and inequality.

\section{Appendix}

\section{A. Aggregation and distribution}

In deriving (25), aggregate (23) from both sides to get

$$
\begin{aligned}
\mathrm{E} k_{t+1}^{i} & =a_{1} \beta \alpha\left(k_{t}\right)^{1-\alpha} \mathrm{E}\left(\epsilon_{t}^{i}\left(k_{t}^{i}\right)^{\alpha}\right) \\
& =a_{1} \beta \alpha\left(k_{t}\right)^{1-\alpha} \mathrm{E}\left(k_{t}^{i}\right)^{\alpha}=a_{1} \beta \alpha \exp \left(0.5 \alpha(\alpha-1) \sigma_{t, k}^{2}\right)
\end{aligned}
$$

since $\epsilon_{t}^{i}$ is i.i.d. and $\mathrm{E} \epsilon_{t}^{i}=1 .^{33}$

\footnotetext{
${ }^{33}$ We also used the fact that:

$$
\begin{aligned}
\ln \mathrm{E}\left(k_{t}^{i}\right)^{\alpha} & =\mathrm{E} \ln \left(k_{t}^{i}\right)^{\alpha}+0.5 \mathrm{~V} \ln \left(k_{t}^{i}\right)^{\alpha} \\
& =\alpha\left(\ln \mathrm{E} k_{t}^{i}-0.5 \mathrm{~V} \ln k_{t}^{i}\right)+0.5 \alpha^{2} \mathrm{~V} \ln \left(k_{t}^{i}\right) \\
& =\ln \left(k_{t}\right)^{\alpha}+0.5 \sigma_{t}^{2} \alpha(\alpha-1)
\end{aligned}
$$
}


To obtain (30), take the log from both sides of (22) and then aggregate:

$$
\mathrm{E} \ln \left(c_{t+1}^{i} / c_{t}^{i}\right)=\mathrm{E} \ln \epsilon_{t+1}^{i}+(\alpha-1) \mathrm{E} \ln k_{t+1}^{i}+\ln a_{1} \beta \alpha\left(k_{t+1}\right)^{1-\alpha}
$$

The left-hand side of (A.2) is given by

$$
\mathrm{E} \ln \left(c_{t+1}^{i} / c_{t}^{i}\right)=\ln \left(c_{t+1} / c_{t}\right)-0.5\left(\sigma_{t+1, c}^{2}-\sigma_{t, c}^{2}\right)
$$

since $c_{t}^{i}$ and $c_{t+1}^{i}$ are lognormally distributed given (3) and (24); $c_{t} \equiv \mathrm{E} c_{t}^{i}, \sigma_{t, c}^{2} \equiv$ $\mathrm{V} \ln c_{t}^{i}{ }^{34}$ On the right-hand side, using the normal-lognormal relationship, we have

$$
\begin{aligned}
\mathrm{E} \ln \epsilon_{t+1}^{i} & =\ln \mathrm{E} \epsilon_{t+1}^{i}-0.5 \mathrm{~V} \ln \epsilon_{t+1}^{i}=-0.5 \nu^{2} \\
\mathrm{E} \ln k_{t+1}^{i} & =\ln \mathrm{E} k_{t+1}^{i}-0.5 \mathrm{~V} \ln k_{t+1}^{i} \\
& =\ln k_{t+1}-0.5 \sigma_{t+1, k}^{2}
\end{aligned}
$$

Substitute these back into (A.2).

To derive (34), first rewrite (21) as

$$
\begin{aligned}
y_{t+1}^{i} & =a_{1} \epsilon_{t+1}^{i} k_{t+1}\left(k_{t+1}^{i} / k_{t+1}\right)^{\alpha} \\
& =a_{1} \epsilon_{t+1}^{i} \beta \alpha\left(y_{t}\right)^{1-\alpha}\left(y_{t}^{i}\right)^{\alpha}
\end{aligned}
$$

since $k_{t+1}=\beta \alpha y_{t}$ and $k_{t+1}^{i}=\beta \alpha y_{t}^{i}$, from (23). Then, aggregate both sides of (A.4) to obtain

$$
\begin{aligned}
y_{t+1} & =a_{1} \beta \alpha\left(y_{t}\right)^{1-\alpha} \mathrm{E}\left(y_{t}^{i}\right)^{\alpha} \\
& \Leftrightarrow \gamma_{t+1, y}=\ln a_{1} \beta \alpha+0.5 \alpha(\alpha-1) \sigma_{t, y}^{2}
\end{aligned}
$$

since $\mathrm{E}\left(y_{t}^{i}\right)^{\alpha}=\left(y_{t}\right)^{\alpha} \exp \left(0.5 \alpha(\alpha-1) \sigma_{t, y}^{2}\right)$. Finally, substitute (31) into (A.5).

${ }^{34}$ Deriving (A.3) is straightforward. First,

$$
\begin{aligned}
\mathrm{E} \ln \left(c_{t}^{i}\right) & =\ln \mathrm{E}\left(c_{t}^{i}\right)-0.5 \mathrm{~V} \ln \left(c_{t}^{i}\right) \\
& =\ln \mathrm{E}\left(c_{t}\right)-0.5 \sigma_{t, c}^{2}
\end{aligned}
$$

Then, do the same for $c_{t+1}^{i}$ and subtract one from the other. 


\section{B. Individual optimal decision with borrowing constraint}

Given (4), (8) and (9), the first-order conditions of the Lagrangian,

$$
\mathrm{E}=\sum_{t=0}^{\infty}\left\{u\left(c_{t}^{i}\right)+\lambda_{t}^{i}\left[y_{t}^{i}+q_{t}^{i} R_{t}-c_{t}^{i}-k_{t+1}^{i}-q_{t+1}^{i}\right]+\mu_{t+1}^{i}\left(q_{t+1}^{i}+\phi y_{t+1}^{i}\right)\right\}
$$

of the $i$ th individual optimization problem are given by

$$
\begin{aligned}
u^{\prime}\left(c_{t}^{i}\right) & =\lambda_{t}^{i} \\
\lambda_{t+1}^{i} \beta r_{t+1}^{i}+\mu_{t+1}^{i} \phi r_{t+1}^{i} & =\lambda_{t}^{i} \\
\lambda_{t+1}^{i} \beta R_{t+1}+\mu_{t+1}^{i} & =\lambda_{t}^{i} \\
q_{t+1}^{i} & =-\phi y_{t+1}^{i}
\end{aligned}
$$

Combining (B.2) and (B.3), we have

$$
\lambda_{t+1}^{i} \beta r_{t+1}^{i} \frac{1-\phi R_{t+1}}{1-\phi r_{t+1}^{i}}=\lambda_{t}^{i}
$$

Substituting this into (B.1), we obtain (10).

If there is no borrowing cost, $\mu_{t+1}^{i}=0$, or the borrowing constraint (9) does not bind, then (B.1) to (B.3) also imply (12) and (13).

\section{References}

Agenor, P.-R., 2010. A theory of infrastructure-led development. Journal of Economic Dynamics and Control 34 (5), 932-950.

Aghion, P., Caroli, E., Garcia-Penalosa, C., 1999. Inequality and economic growth: The perspective of the new growth theories. Journal of Economic Literature 37 (4), 1615-1660.

Aghion, P., Howitt, P., 1998. Endogenous growth theory. Cambridge and London: MIT Press.

Aiyagari, S. R., 1994. Uninsured idiosyncratic risk and aggregate saving. The Quarterly Journal of Economics 109 (3), 659-684.

Angeletos, G.-M., Calvet, L.-E., 2005. Incomplete-market dynamics in a neoclassical production economy. Journal of Mathematical Economics 41 (4-5), 407-438. 
Angeletos, G.-M., Calvet, L.-E., 2006. Idiosyncratic production risk, growth and the business cycle. Journal of Monetary Economics 53 (6), 1095-1115.

Arrow, K. J., 1962. The economic implications of learning by doing. Review of Economic Studies 29 (June), 155-173.

Atkeson, A., Phelan, C., April 1994. Reconsidering the costs of business cycles with incomplete markets. Working Paper 4719, National Bureau of Economic Research.

Bandyopadhyay, D., Tang, X., 2011. Parental nurturing and adverse effects of redistribution. Journal of Economic Growth 16 (1), 71-98.

Banerjee, A. V., Duflo, E., 2004. Do Firms Want to Borrow More? Testing Credit Constraints Using a Directed Lending Program. Working Paper MIT.

Banerjee, A. V., Newman, A. F., 1993. Occupational choice and the process of development. The Journal of Political Economy 101 (2), 274-298.

Barro, R. J., 1990. Government spending in a simple model of endogeneous growth. The Journal of Political Economy 98 (5), S103-S125.

Barro, R. J., Sala-i Martin, X., 2004. Economic Growth, 2nd Edition. The MIT Press, Cambridge, Massachusetts London, England.

Bartelsman, E., Haltiwanger, J., Scarpetta, S., 2013. Cross-country differences in productivity: The role of allocation and selection. American Economic Review 103 (1), 305-34.

Basu, P., Getachew, Y., 2015. An adjustment cost model of social mobility. Journal of Macroeconomics 44, $177-190$.

Benabou, R., 1996. Inequality and Growth. NBER Macroeconomics Annual, Volume 11, MIT Press.

Benabou, R., 2002. Tax and education policy in a heterogeneous-agent economy: What levels of redistribution maximize growth and efficiency? Econometrica $70(2), 481-517$.

Bodman, P., Campbell, H., Le, T., 2012. Public investment, taxation, and long-run output in economies with multi-level governments. Economic Modelling 29 (5), $1603-1611$. 
Boucekkine, R., Licandro, O., Puch, L. A., del Rio, F., 2005. Vintage capital and the dynamics of the AK model. Journal of Economic Theory 120 (1), 39-72.

Carroll, C. D., Overland, J., Weil, D. N., 1997. Comparison utility in a growth model. Journal of Economic Growth 2 (4), 339-367.

Carroll, C. D., Overland, J., Weil, D. N., 2000. Saving and growth with habit formation. The American Economic Review 90 (3), 341-355.

Caselli, F., Ventura, J., 2000. A representative consumer theory of distribution. The American Economic Review 90 (4), 909-926.

Chatterjee, S., Turnovsky, S. J., 2012. Infrastructure and inequality. European Economic Review 56 (8), 1730-1745.

Clark, G., Cummins, N., 2012. What is the True Rate of Social Mobility? Surnames and Social Mobility, England, 1800-2012. Working Paper, http://www.econ.ucdavis.edu/faculty/gclark/research.html.

De Gregorio, J., 1996. Borrowing constraints, human capital accumulation, and growth. Journal of Monetary Economics 37 (1), $49-71$.

Frankel, M., 1962. The production function in allocation and growth: A synthesis. The American Economic Review 52 (5), 996-1022.

Galor, O., Moav, O., 2004. From physical to human capital accumulation: Inequality and the process of development. Review of Economic Studies 71 (4), 1001-1026.

Galor, O., Zeira, J., 1993. Income distribution and macroeconomics. The Review of Economic Studies 60 (1), 35-52.

Garcia-Penalosa, C., Turnovsky, S. J., 2007. Growth, income inequality, and fiscal policy: What are the relevant trade-offs? Journal of Money, Credit, and Banking 39 (2-3), 369-394.

Getachew, Y. Y., 2010. Public capital and distributional dynamics in a two-sector growth model. Journal of Macroeconomics 32 (2), 606-616.

Getachew, Y. Y., Turnovsky, S. J., 2015. Productive government spending and its consequences for the growth-inequality tradeoff. Research in Economics. URL http://dx.doi.org/10.1016/j.rie.2015.09.001 
Giannini, M., 2003. Accumulation and distribution of human capital: the interaction between individual and aggregate variables. Economic Modelling 20 (6), $1053-1081$.

Glomm, G., Ravikumar, B., 1994. Public investment in infrastructure in a simple growth model. Journal of Economic Dynamics and Control 18 (6), 1173-1187.

Gomez, M. A., 2008. Convergence speed in the Ak endogenous growth model with habit formation. Economics Letters 100 (1), 16-21.

Guerrini, L., 2010. Transitional dynamics in the ramsey model with AK technology and logistic population change. Economics Letters 109 (1), 17-19.

Jappelli, T., Pagano, M., 1994. Saving, growth, and liquidity constraints. The Quarterly Journal of Economics 109 (1), 83-109.

Jones, L. E., Manuelli, R. E., 1990. A convex model of equilibrium growth: Theory and policy implications. Journal of Political Economy 98 (5), 1008-1038.

Krebs, T., 2003. Growth and welfare effects of business cycles in economies with idiosyncratic human capital risk. Review of Economic Dynamics 6 (4), 846 868.

Krusell, P., Mukoyama, T., Sahin, A., Anthony A. Smith, J., 2009. Revisiting the Welfare Effects of Eliminating Business Cycles. Review of Economic Dynamics $12(3), 393-402$.

Loury, G. C., 1981. Intergenerational transfers and the distribution of earnings. Econometrica 49 (4), 843-867.

Mankiw, N. G., Romer, D., Weil, D. N., 1992. A contribution to the empirics of economic growth. Quarterly Journal of Economics 107 (2), 407-437.

Matsuyama, K., 2000. Endogenous inequality. The Review of Economic Studies 67 (4), 743-759.

Mazumder, B., 2005. Fortunate sons: New estimates of intergenerational mobility in the united states using social security earnings data. The Review of Economics and Statistics 87 (2), 235-255.

McKenzie, D., Woodruff, C., 2006. Do entry costs provide an empirical basis for poverty traps? evidence from mexican microenterprises. Economic Development and Cultural Change 55 (1), 3-42. 
Mel, S. d., McKenzie, D., Woodruff, C., 2008. Returns to capital in microenterprises: Evidence from a field experiment. The Quarterly Journal of Economics 123 (4), $1329-1372$.

Neumann, J. V., 1937. "Uber ein okonomisches Gleichungssystem und eine Verallgemeinerung des Brouwerschen Fixpunktsatzes." Ergebnisse eines Mathematischen Kolloquiums, 8, translated by Karl Menger as "A model of general economic equilibrium". The Review of Economic Studies (1945) 13 (1), 1-9.

Rebelo, S., 1991. Long-run policy analysis and long-run growth. Journal of Political Economy 99 (3), 500-521.

Romer, P. M., 1986. Increasing returns and long-run growth. Journal of Political Economy 94 (5), 1002-1037.

Shin, I., 2012. Income inequality and economic growth. Economic Modelling 29 (5), $2049-2057$.

Solon, G., 1992. Intergenerational income mobility in the united states. The American Economic Review 82 (3), 393-408.

Storesletten, K., Telmer, C. I., Yaron, A., 2001. The welfare cost of business cycles revisited: Finite lives and cyclical variation in idiosyncratic risk. European Economic Review 45 (7), $1311-1339$.

Tamura, R., 1991. Income convergence in an endogeneous growth model. Journal of Political Economy 99 (3), 522-540.

Tamura, R., Dwyer, G. P., Devereux, J., Baier, S., 2014. Economic growth in the long run. Working paper.

Turnovsky, S. J., 1996. Fiscal policy, adjustment costs, and endogenous growth. Oxford Economic Papers 48 (3), 361-381.

Turnovsky, S. J., 1997. Equilibrium Growth in a Small Economy Facing an Imperfect World Capital Market. Review of Development Economics 1 (1), 1-22.

Turnovsky, S. J., 1997. Fiscal policy in a growing economy with public capital. Macroeconomic Dynamics 1 (3), 615-639.

Turnovsky, S. J., Bianconi, M., 2005. Welfare gains from stabilization in a stochastically growing economy with idiosyncratic shocks and flexible labor supply. Macroeconomic Dynamics 9, 321-357. 
UNU-WIDER, 2007. World Income Inequality Database, Version 2.0b. UNUWIDER.

Tables and Figures 
Table 1: Benchmark values

\begin{tabular}{|l|l|}
\hline $\begin{array}{l}\text { Preference, production } \\
\text { and policy parameters }\end{array}$ & $\begin{array}{l}\beta=0.96, \alpha=0.33, \theta=0.1 \& 0.2, \\
\eta=-5.7 \text { to } 1.5, \tau=0.05\end{array}$ \\
\hline Inequality parameter & $v^{2}=0.16$ \\
\hline
\end{tabular}

Table 2: Mobility, inequality and public policy

\begin{tabular}{lllllllll}
\hline$\eta$ & & \multicolumn{3}{c}{$\theta=0.1$} & & \multicolumn{3}{c}{$\theta=0.2$} \\
\cline { 1 - 4 } \cline { 7 - 8 } \cline { 7 - 9 } & $\kappa$ & $\kappa^{2}$ & $\sigma^{2}$ & & $\kappa$ & $\kappa^{2}$ & $\sigma^{2}$ \\
\hline \hline 1.5 & & 0.18 & 0.0324 & 0.1654 & & 0.03 & 0.0009 & 0.1601 \\
1 & & 0.23 & 0.529 & 0.1689 & & 0.13 & 0.0169 & 0.1628 \\
0 & & 0.33 & 0.1089 & 0.1796 & & 0.33 & 0.1089 & 0.1796 \\
-0.5 & & 0.43 & 0.1849 & 0.1963 & & 0.53 & 0.2809 & 0.2225 \\
-1 & & 0.48 & 0.2304 & 0.2079 & & 0.63 & 0.3969 & 0.2653 \\
-2 & & 0.53 & 0.2809 & 0.2225 & & 0.73 & 0.5329 & 0.3425 \\
-2.35 & & 0.57 & 0.3192 & 0.2350 & & 0.8 & 0.64 & 0.444 \\
\hline
\end{tabular}


Figure 1: Growth with deterministic and stochastic shocks
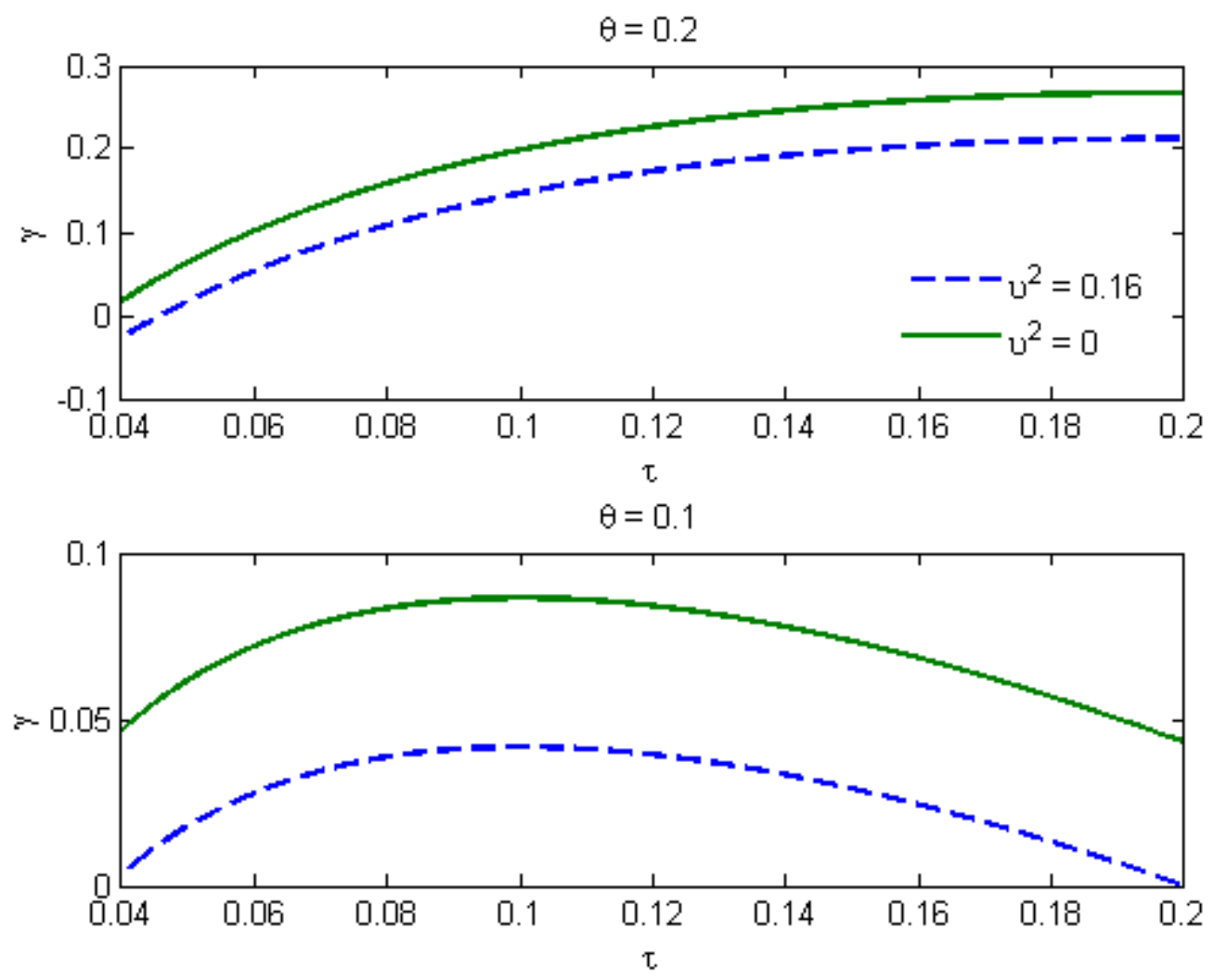
Figure 2: Growth dynamics in $A k$ model with borrowing constraints and Stone-Geary utility

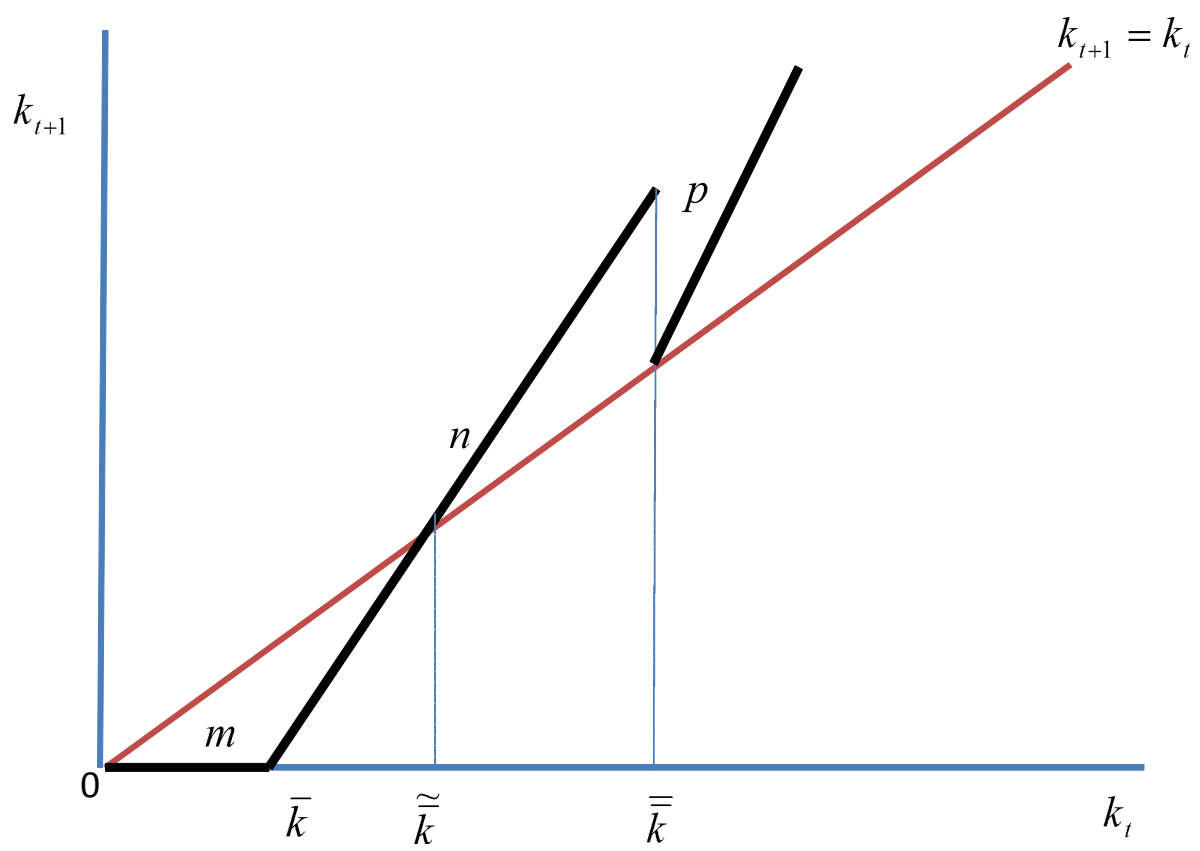

